\title{
An Analysis on Qualitative Bankruptcy Prediction Rules using Ant-Miner
}

\author{
A. Martin \\ Research Scholar, Department of Banking Technology, Pondicherry University, Puducherry, India \\ E-mail: jayamartin@yahoo.com,cudmartin@gmail.com \\ T. Miranda Lakshmi \\ Research Scholar, Department of Computer Science, Bharathiyar University, Coimbatore, India \\ E-mail: cudmiranda@gmail.com \\ Associate Prof., Department of Banking Technology, Pondicherry University, Puducherry, India \\ E-mail: prasanna_v@yahoo.com
}

\begin{abstract}
Qualitative bankruptcy prediction rules represent experts' problem-solving knowledge to predict qualitative bankruptcy. The objective of this research is predicting qualitative bankruptcy using antminer algorithm. Qualitative data are subjective and more difficult to measure. This approach uses qualitative risk factors which include fourteen internal risk factors and sixty eight external risk factors associated with it. By using these factors qualitative prediction rules are generated using ant-miner algorith $m$ and the influence of these factors in bankruptcy is also analyzed. Ant-Miner algorithm is a application of ant colony optimization and data mining concepts. Qualitative rules generated by ant miner algorithm are validated using measure of agreement. These prediction rules yields better accuracy with lesser number of terms than previously applied qualitative bankruptcy prediction methodologies.
\end{abstract}

Index Terms - Ant-Miner, Qualitative Bankruptcy Prediction, Experts Decision Analysis, Data Mining, Kappa Test, Measure of Agreement, Bankruptcy

\section{Introduction}

Bankruptcy is financial failure of a business [1] and when an organization not able to pay its debts is called as bankruptcy. Impact of bankruptcy has shown disastrous outcomes and its affects whole community [2]. The impact of bankruptcy clearly states the need for an efficient model to predict bankruptcy. Bankruptcy prediction (BP) refers to prediction of business failure through financial [4-12] and nonfinancial variables [13-18, 43]. BP is one of the most important decisions in financial decision making [19]. BP is studied extensively in the accounting and finance literature [20] Different approaches [42] have been applied for bankruptcy prediction. Statistical Approaches in which univariate analysis (Beaver, 1966) [22], multivariate discriminant analysis (Altman, 1968) [21], log istic regression approach (Ohlson, 1980) [23] and factor analysis technique (West, 1985) [24] have been applied. Another approach is artificial intelligence and soft computing approaches in which artificial neural networks [25], Support vector machines [26] Bayesian network models [27] and many other AI techniques have been applied. Other then these approaches swarm intelligence approaches [28-29, 35, 37] and hybrid methods and ensemble methods [8], [25] [43] have been applied to predict bankruptcy.

In all these approaches bankruptcy has been predicted by using two kinds of parameters such as quantitative parameters and qualitative parameters. Many quantitative bankruptcy prediction methods are available. These methods have improved the prediction accuracy of quantitative bankruptcy. Many organizations have applied these methodologies to predict bankruptcy. Irrespective these proven methodologies for quantitative bankruptcy prediction, organizations have tended to fail very often. When organizations starts give importance for indirect parameters, the occurrence of failure may be reduced [28] and these indirect parameters which cause bankruptcy called as qualitative bankruptcy parameters [18]. We have found very limited work on qualitative parameters which causes the bankruptcy. In this qualitative bankruptcy prediction method, we are applying 14 outer risk parameters and 68 inner risk parameters [18], [30], [32]. This research induces qualitative bankruptcy rules using Ant-Miner algorithm

Ant-Miner is an application of ACO in data mining [34-35, 38, 42]. Ant Miner algorith $m$ is a combination of both Ant colony and data mining concepts. It is an ant-based algorithm for the discovery of classification rules. Ant-Miner has proved to be a very promising 
technique for classification rules discovery. Ant-Miner generates a fewer number of rules, fewer terms per each rule and performs competitively in terms of performance compared to other classification algorithms [33, 43-44].

The rest of the paper is organized as follows, section 2 describes the prior research on qualitative bankruptcy prediction, section 3 describes list of qualitative parameters, section 4 describes the ant miner algorith $\mathrm{m}$, section 5 describes the experimental design, section 6 describes the results and section 7 concludes the paper.

\section{Literature Survey}

\subsection{Ant-Miner Algorithm and its Applications}

Ant-Miner is an application of ACO with the classification task of data mining. It has been introduced as an ant-based algorithm for the discovery of classification rules [34-35] Ant-Miner has proved to be a very promising technique for classification rules discovery. Ant-Miner generates a fewer number of rules, fewer terms per each rule and performs competitively in terms of performance. There are many researches undergone in the area of bankruptcy prediction. There are many studies regarding the analysis of qualitative and quantitative bankruptcy prediction. These studies include statistical techniques as well as intelligent techniques to predict bankruptcy. This literature survey describes about various studies on qualitative bankruptcy prediction [37-41].

The research on data mining with an ant colony optimization proposes an algorithm for data mining called Ant-Miner (ant-colony-based data miner). It compares the performance of Ant-Miner with CN2, a well-known data mining algorith $\mathrm{m}$ for classification, in six public domain data sets. The results provide evidence that the rule lists discovered by Ant-Miner are considerably simpler (smaller) than those discovered by $\mathrm{CN} 2$. The conclusion on this research indicates that Ant-Miner obtained better results in four data sets, whereas $\mathrm{CN} 2$ obtained a considerably better result in one data set. Therefore, Ant-Miner minimizes the number of discovered rules and rule terms (conditions) in order to improve clarity of the discovered knowledge [33-34, 41].

The research on an ant colony algorithm for classification rule discovery, proposes an algorith $\mathrm{m}$ for rule discovery called Ant-Miner (ant colony-based data miner). The result indicates that rule sets discovered by Ant-Miner are simpler (smaller) than the rule sets discovered by C4.5 [35]. A research on new classification-rule pruning procedure for an ant colony algorithm proposes a new rule pruning procedure for Ant-Miner. The results indicates that the rules which are generated by new pruning procedure is considerably shorter, and so simpler (more easily interpretable by the users) than the rules discovered by the original antminer [41]. The thesis on ant colony optimization and the ant miner algorithm describes premature converge on solutions obtained by ant-miner [44]. This literature study indicates the efficiency and suitability of antminer algorithm for the development qualitative bankruptcy prediction rules using ant-miner algorithm.

\subsection{Qualitative Bankruptcy Prediction}

The research on discovery of qualitative bankruptcy rules using Genetic Algorithm (GA) demonstrated the genetic based data mining approach to discover qualitative prediction rules from experts' decision process. This study is the first work on GAs for the purpose of discovering experts' qualitative knowledge on bankruptcy. The fitness function of the GA is the composite measure to discover decision rules that satisfy accuracy and coverage. This work has generated expert decision rules for qualitative bankruptcy, but it has redundant and overlapping structure. Since GA is applied to construct rules, learning approach was not applied in this methodology. In this approach only six external factors have been considered to generate the rules and the performance of this method is limited traditional genetic approach [18]. The qualitative factors which are applied in this work have been collected from various firms which are applied to analyze its qualitative performance [30-32].

\section{Qualitative Bankruptcy Parameters}

Bankruptcy prediction is the art of predicting financial distress of a business, an organization or an individual. Bankruptcy is a legal status of a person or an organization that cannot repay the debts it owes to its creditors. Bankruptcy prediction is an active area of research in finance as well as in any business. The qualitative parameters that are included in the paper are described in Table 1.

Table 1: List of qualitative bankruptcy parameters

\begin{tabular}{|c|c|}
\hline MAIN PARAMEIERS & SUB PARAMETERS \\
\hline $\begin{array}{l}\text { Industry Risk(IR) } \\
\text { (Myoung and Ingoo,2003) }\end{array}$ & 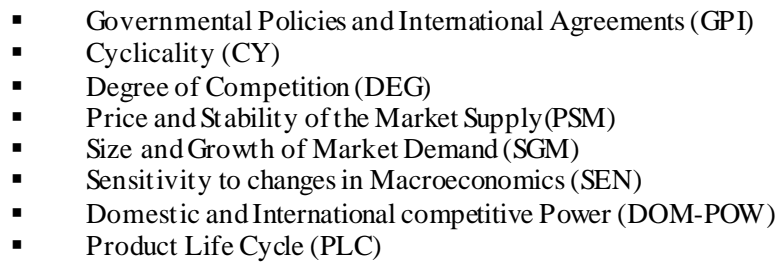 \\
\hline
\end{tabular}




\begin{tabular}{|c|c|}
\hline $\begin{array}{l}\text { Management Risk(MR) } \\
\text { (Myoung and Ingoo,2003) }\end{array}$ & $\begin{array}{ll} & \text { Ability and Competence of management (ACM) } \\
: & \text { Stability of Management (SM) } \\
: & \text { Relationship between Management/Owner (REL-MO) } \\
: & \text { Growan Resource Management (HRM) } \\
\text { AF) } & \text { Short and long term Business Planning, Achievement and Feasibility (SL-TERM } \\
\end{array}$ \\
\hline $\begin{array}{l}\text { Financial Flexibility (FF) } \\
\text { (Myoung and Ingoo,2003) }\end{array}$ & $\begin{array}{ll}- & \text { Direct Financing (DF) } \\
\text { - } & \text { Indirect Financing(IF) } \\
\text { Other financing [Affiliates, Owner, Third Parties] (OF) }\end{array}$ \\
\hline $\begin{array}{l}\text { Credibility(CR) } \\
\text { (Myoung and Ingoo,2003) }\end{array}$ & $\begin{array}{ll}\text { Credit Hist ory }(\mathrm{CH}) \\
\quad \text { Reliability of Information (RI) }\end{array}$ \\
\hline $\begin{array}{l}\text { Competitiveness (CO) } \\
\text { (Myoung and Ingoo,2003) }\end{array}$ & $\begin{array}{ll}\text { - } & \text { Market Position (MP) } \\
\text { Differentiated Strategy (DIFF-S) }\end{array}$ \\
\hline $\begin{array}{l}\text { Operating Risk (OR) } \\
\text { (Myoung and Ingoo,2003) }\end{array}$ & 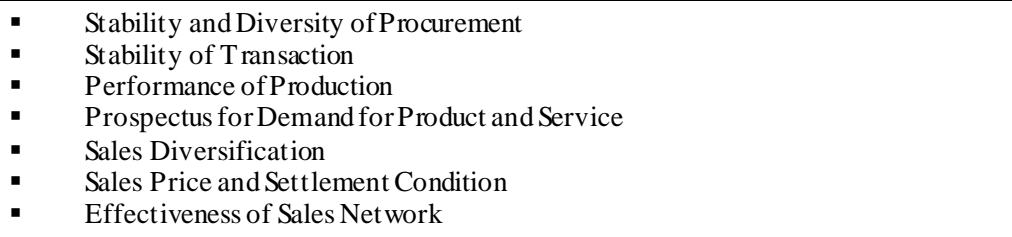 \\
\hline $\begin{array}{l}\text { Common Business } \\
\text { Performance Analysis Parameters } \\
\text { (CBP) (Yi-Chung, 2009) }\end{array}$ & 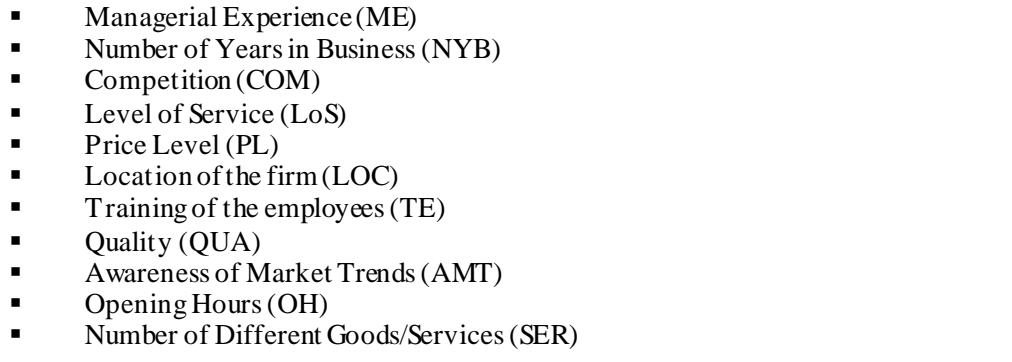 \\
\hline $\begin{array}{l}\text { Firm Default Parameters(FD) } \\
\text { (Kasirga and Omur,2009) }\end{array}$ & 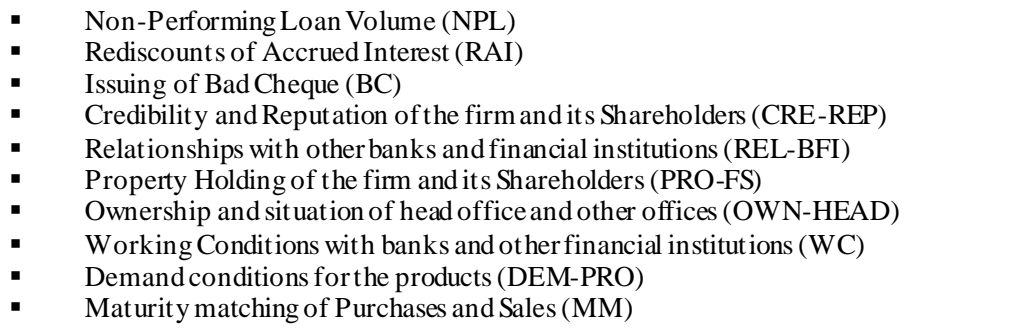 \\
\hline $\begin{array}{l}\text { Reorganization Parameters(RP) } \\
\text { (Nesi et.al, 2009) }\end{array}$ & $\begin{array}{ll}\text { External Environment }(\mathrm{EE}) \\
\quad \text { Quality of Enterprise }(\mathrm{QE})\end{array}$ \\
\hline $\begin{array}{l}\text { Pricing (PP) } \\
\text { (Nesi et.al, 2009) }\end{array}$ & $\begin{array}{ll}- & \text { Deposit Rate(DR) } \\
& \text { Transaction fee (TF) }\end{array}$ \\
\hline $\begin{array}{l}\text { Differentiation Parameters(DP) } \\
\text { (Nesi et.al, 2009) }\end{array}$ & $\begin{array}{ll}: & \text { International Linkages (IL) } \\
: \quad & \text { International Image and Reputation (IIR) } \\
\text { - } \quad \text { Penpany Privilege (CP) } & \text { Working Hours (WH) }\end{array}$ \\
\hline $\begin{array}{l}\text { Marketing Parameters(MP) } \\
\text { (Nesi et.al, 2009) }\end{array}$ & $\begin{array}{ll}- & \text { Service Quality (SQ) } \\
: & \text { Quality of theEmployees (QE) } \\
\text { - } & \text { Markonding to the Cust omer Needs (RCN) }\end{array}$ \\
\hline $\begin{array}{l}\text { Delivery Parameters(DEP) } \\
\text { (Nesi et.al, 2009) }\end{array}$ & $\begin{array}{ll}\text { Transaction Duration (TD) } \\
\text { Internet Banking (IB) }\end{array}$ \\
\hline $\begin{array}{l}\text { Productivity (PRP) } \\
\text { (Nesi et.al, 2009) }\end{array}$ & - $\quad$ Productivity \\
\hline
\end{tabular}

Table 1 describes about various qualitative parameters which have been applied in various business to analyze qualitative bankruptcy performance. Qualitative parameters are subjective in nature as it can be measured as low, medium and high. To evaluate qualitative parameters, we need help from experts.
Experts will be evaluating the parameters based on their decision and this analysis depends on the history, the values will not be accurate but approximate. The scores and ranks to indicate the importance of the parameters are High (100-66), Medium (65-46) \& Low (45-0). Expert analyses have been conducted for these 
parameters from various banks using questioner. The questioner which is applied for industry risk has been depicted in figure 1.

I. Industry Risk (IR)

IR is measured by the stability and the growth of the industry, the degree of competition over the industry, and the overall conditions of the industry.

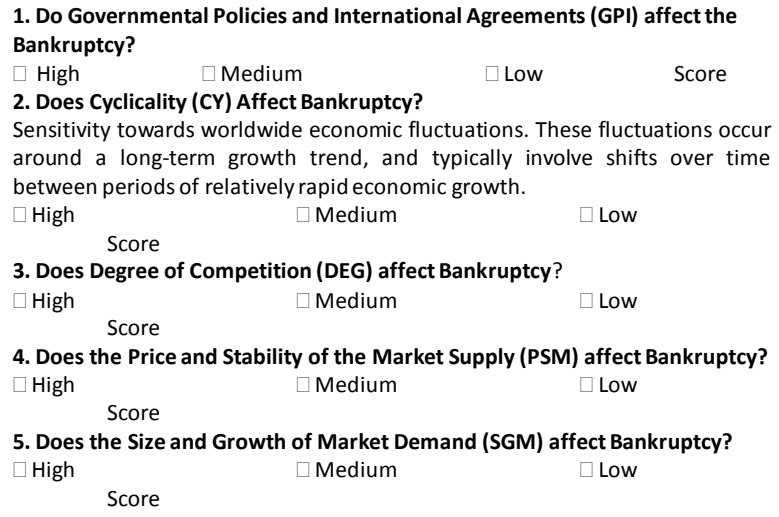

Fig. 1: Questioner applied for Industry Risk

In the same way questioner which is applied for management risk has been described in figure 2 .

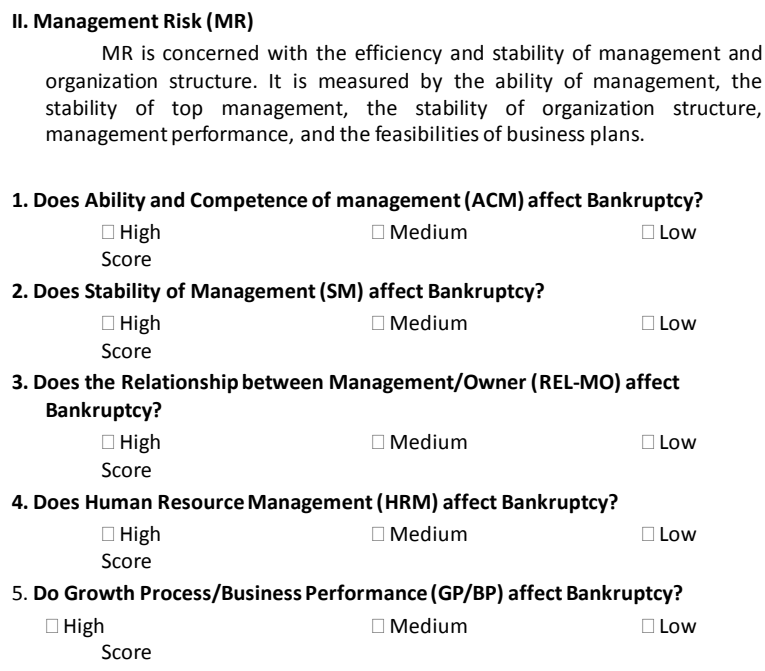

Fig. 2: Questioner applied for Management Risk

The next section describes the ant-miner algorithm with its working procedure.

\section{Working Model of Ant-Miner Algorithm}

Ant Miner is an ACO based rule induction algorith $m$ [33-34,42]. The first application of ACO for the classification task was reported in where the authors introduce the Ant Miner algorith $m$ for the discovery of classification rules. The aim of this algorithm is to induce simple rules of the form if rule antecedent then rule consequent, where the rule antecedent is a conjunction of terms. Ant miner algorithm is a rule induction algorithm by which the qualitative bankruptcy rules are framed. Each classification rule is of the form:

\section{If $<$ Term1 And Term2 And Term3.... > Then 〈Class $\rangle$}

Each term is a triplet<attribute, operator, value >,

Where,

Value is the value belonging to the domain of the attribute.

The operator element in the triplet is the relational type.

Usually the operator element is always '='

In this algorithm the rules are generated and the generated rules are pruned. The pruned rules are considered as the optimal rules. After the pruning process the pheromone updating is done both locally and globally. The steps of Ant-Miner algorith m [33-34] have been described in figure 2 ,

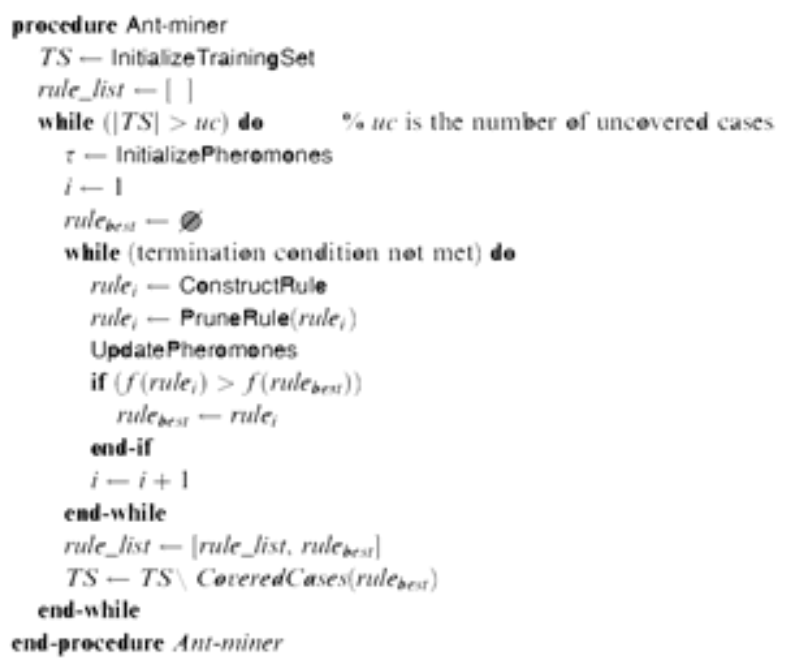

Fig. 3: Ant-Miner Algorithm

The working procedure of ant-miner has been described as follows,

Initiation of training set; training set will contain all the values of parameters (i.e) all training cases. An empty rule list is in itiated namely DiscoveredRuleList[].

While(training set $>$ Max uncovered cases)

Step $i: \quad t=1 / *$ ant index*/

Step ii: $j=1 / *$ convergence test index*/

Step iii: Initiate the pheromone for all the parameters

Repeat

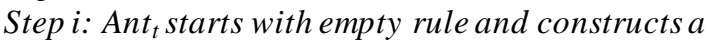
classification rule $R_{t}$ by adding one term at a time to the current rule 
Step ii: Prune rule $R_{t}$

Step iii: Update the pheromone contents of all trails by increasing the pheromone in the trail followed by Ant $t_{t}$, and decreasing in other trails

Step iv: if $\left(R_{t}=R_{t-1}\right)$ then increment $j ; j=j+1 / *$ update convergence test $*$ /

Step v: else $j=1$

Step vi: Increment the ant index; $t=t+1$ Until( $t \geq$ No.of Ants) Or ( $j \geq$ No of Rules Converge); Choose the best rule $R_{\text {best }}$ among all rules $R_{t}$ constructed by all ants

Step viii: $\quad$ Add rule $R_{\text {best }}$ to DiscoveredRuleList

Step ix: TrainingSet=TrainingSet $-\{$ set of cases correctly covered by $R_{\text {best }}$ )

Step ii in Repeat loop is for pruning the generated rules. There is an original ant miner pruning for freshly generated rule by the current ant and tries to improve its quality by removing irrelevant terms from the rule antecedent [40]. This process is done iteratively by removing one term at a time. The iterative process will stop when there is no more improvement in the quality of the generated rules while there is removal of terms.

\section{Execute_Pruning $=$ true $/ *$ A Boolean variable */}

While( Execute_Pruning $=$ true $) \& \&$ (No.of rules in current antecedent is greater than 1)

Step $i$ : For each term $t_{i}$ in the current rule to be pruned, temporarily remove the term $t_{i}$ and evaluate the quality

Step ii: Reinstate term $t_{i}$ in the rule antecedent

If Rule quality is improved with respect to original rule's quality in some iteration of For loop

Then permanently remove the term whose removal improves the quality of the rule

Else Set Execute_Pruning=False
The time taken by the ant mining pruner is sensitive to the number of attributes added. This is due the fact that the larger the nu mber of attributes in the data being mined, in general the larger the number of terms in the constructed rule before pruning, and so the larger number of iterations in the loops. The quality of the rule can be calculated by the formula below:

Rule Quality =

Sensitivity $\times$ Specificity $=\frac{\mathrm{TP}}{\mathrm{TP}+\mathrm{FN}} \times \frac{\mathrm{TN}}{\mathrm{TN}+\mathrm{FP}}$

Where,

$T P=$ true positives, the number of cases covered by the rule that have the class predicted by the rule.

$F P=$ false positives, the number of cases covered by the rule that have the class different from the class predicted by the rule

$F N=$ false negative, the number of cases not covered by the rule but have class predicted by the rule

$T N=$ true negative, the number of cases not covered by the rule and that do not have class predicted by the rule

After the pruning method, the best among the rules will be found and the performance analysis of the predicted rules will be known. Finally, the comparisons of rules generated by both the algorithms are done and the performance will be calculated.

\section{Experimental Design}

\subsection{Data Design}

The value for these qualitative parameters has been collected from various experts belongs to banks. These parameters are framed as questionnaire and the data have been collected from the experts. Tab le 2 describes the parameters with its values have been collected from various banks.

Table 2: Qualitative bankruptcy prediction parameters with expert analysis

\begin{tabular}{|l|c|c|c|c|c|c|c|c|c|}
\hline \multicolumn{1}{|c|}{ BANKS } & IR & MR & FF & CR & CO & OR & CBF & FD & RP \\
\hline Syndicate Bank & mid & mid & mid & mid & mid & mid & mid & mid & mid \\
\hline Karnataka Bank & mid & mid & High & mid & mid & mid & mid & mid & mid \\
\hline Indian Overseas Bank & mid & mid & High & mid & mid & High & High & mid & mid \\
\hline Indian Overseas Bank & High & mid & High & mid & mid & mid & High & mid & High \\
\hline Karur Vysya Bank & High & High & mid & High & High & High & mid & High & mid \\
\hline UCO Bank & low & mid & low & mid & low & mid & mid & mid & mid \\
\hline Vijaya Bank & high & high & high & mid & low & high & high & mid & mid \\
\hline ING Vysya Bank & mid & high & mid & high & low & mid & mid & mid & high \\
\hline Axis Bank & mid & high & mid & mid & mid & high & mid & mid & mid \\
\hline Vijaya Bank & mid & high & mid & low & mid & mid & high & high & low \\
\hline Vijaya Bank & high & mid & high & mid & mid & high & high & mid & mid \\
\hline
\end{tabular}


Qualitative parameters with its values have been described in Table 2. To generate qualitative bankruptcy prediction rules using ant-miner we have selected parameters from the expert analysis. According to expert analysis the six parameters have been considered as most important parameters to induce rules such as Industry Risk (IR), Management Risk (MR), Financial Flexibility (FF), Credibility (CR), Competitiveness (CO) and Operating Risk (OR). Among the 14 qualitative bankruptcy parameters six parameters have been considered to generate bankruptcy prediction rules. The next section describes about experimentation design of ant-miner algorith $m$ to induce rules for qualitative bankruptcy prediction.

\subsection{Experimentation of Ant-Miner}

The ant miner algorithm is internally split into two parts for convenient implementation. First is for the generation of rules and second part is for the pruning of the generated rules. Ant-Miner algorith $m$ applied for the discovery of classification rules. The first application of ACO for the classification task has been applied on Medical Data set retrieved from UCI repository. The applied data set are $\mathrm{W}$ isconsin breast cancer, Cleveland heart disease and Hepatitis [33-34]. From these dataset classification rules have been generated using ant-miner. In this experiment we are consideration bankruptcy data which are collected from various banks to induce bankruptcy prediction rules. For this experiment we have applied GUI Ant-Miner. GUI Ant-Miner is a tool for extracting classification rules from data.

\section{Results and Discussion}

Qualitative bankruptcy prediction rules are generated using Ant-Miner algorithm. The generated rules have been described in figure 4 .

\footnotetext{
- Rule1 IF FF is high and CR is high and CO is mid THEN Nonbankrupt

- Rule2 IF FF is low and CR is low and CO is low and OP is low THEN Bankrupt

Rule3 IF FF is high and CO is high THEN Nonbankrupt

Rule4 IF IR is mid and CR is mid and CO is high THEN Nonbankrupt

- Rule5 IF IR is mid and MR is mid and FF is mid and CO is mid and OP is mid THEN Nonbankrupt

- Rule6 IF MR is high and CR is high and CO is high THEN Nonbankrupt

Rule7 IF MR is low and FF is low and CR is low CO is low THEN Bankrupt

Rule8 IF IR is high and MR is high and $C O$ is high THEN Nonbankrupt

Rule9 IF IR is mid and CO is high and OP is mid THEN Nonbankrupt

- Rule10 IF MR is low and FF is low and CR is low and CO is low and OP is mid THEN Bankrupt
}

Fig. 4: Qualitative bankruptcy rules induced by Ant-Miner

From this experiment we have obtained different rules to predict the qualitative performance of the business. These generated rules have been applied to predict bankruptcy qualitatively. Rule 1 indicates that financial flexibility is high and credibility is high and Competitiveness is high then the business would not bankrupt. Whereas Rule 2 indicates that financial flexibility is low and credibility is low and Competitiveness is low and operating risk is medium then the business may bankrupt. Rule 3 indicates that financial flexibility is high and competitiveness is high then the business would not bankrupt. These rules can be applied various organizations and bankruptcy status can be identified by using these rules. The qualitative performance of business or any organization can be predicted using these rules. These generated classified rules can reveal the state of the organization.

\subsection{KAPPA TEST - Measure of Agreement}

It is important to measure the agreement between the classification made by expert and the classifier. This measure indicates the degree to which the subjectivity of experts is incorporated in the model [18]. We adopt Cohen's kappa (1960) as the "measure of agreement". Cohen's kappa measures the agreement between two rater (e.g. an expert and a data mining technique) classifying the same set of cases. Cohen's kappa defines the "measure of agreement" - It depends upon the percentage of matches in each class. A kappa value of 1 indicates a perfect agreement and a kappa value of 0 indicates that agreement is no better.

The result of this experiment has been verified with kappa test to evaluate measure of agreement. The measure of agree ment obtained using kappa test for antminer is 0.9042 which is very near to perfect agree ment. The measure of agreement obtained for ant-miner is compared with previous methodologies which have been applied for qualitative bankruptcy prediction. The comparative analysis of ant-miner with other techniques for kappa test has been depicted in figure 5 .

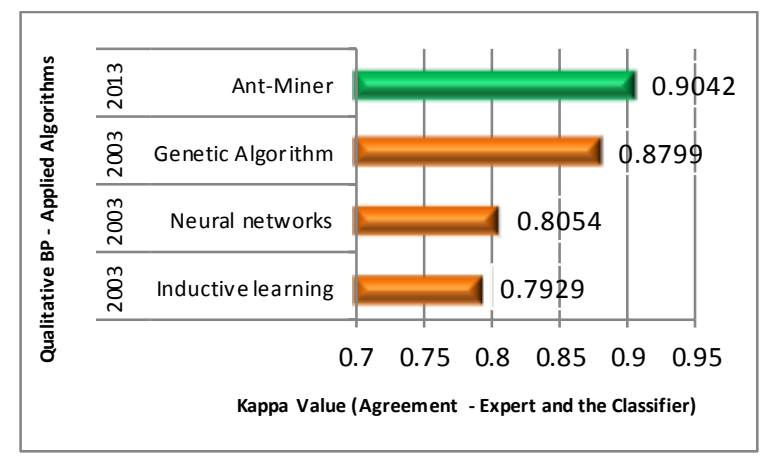

Fig. 5: Ant-Miner \& Other Methodologies for Qualitative Bankruptcy Classification

The graph which is depicted in figure 4 indicates that expert decision making knowledge has been incorporated by ant-miner is high compared to other methodologies. Thus the rules generated by ant-miner can be applied to predict bankruptcy qualitatively. 


\section{Conclusion}

In this research the qualitative bankruptcy prediction rules have been induced by classifying bankruptcy into different classes. For this classification task ant-miner has been applied. The validation of the results has been verified using kappa test based on the factor measure of agreement. In this research data has been validated using 10 fold cross validation. The quality of generated rules has been verified by using rule pruning. The quality of rules can be enhanced by using different rule pruning methodologies. In ant-miner the accuracy of rules can be improved by conducting experiment with larger data set.

\section{References}

[1] James A. Ohlson, Financial Ratios and the Probabilistic Prediction of Bankruptcy, Journal of Accounting Research, Vol. 18, No. 1, Spring, 1980, Page 109 of 109-131

[2] Timo Salmi \& Teppo Martikainen. (2005). A Review of the Theoretical and Empirical Basis of Financial Ratio Analysis. The Finnish Journal of Business Economics, 4(94), 426-448.

[3] Hui Li , Jie Sun. (2011). Principal component case-based reasoning ensemble for business failure Prediction. Elsevier Journal of Information \& Management, 48, pp. 220-227.

[4] Philippe du Jardin. (2010). Predicting bankruptcy using neural networks and other classification methods: The influence of variable selection techniques on model accuracy. Elsevier Journal of Neurocomputing, 73, pp. 2047-2060.

[5] Martin.A, D.Maladhy, V.Prasanna Venkatesan, A framework for business intelligence application using ontological classification, International Journal of Engineering Science and Technology, Vol. 3 No. 2 (2011a), pp. 1213-1221.

[6] Martin.A, M. Manjula and Dr. V.Prasanna Venkatesan, A Business Intelligence Model to Predict Bankruptcy using Financial Domain Ontology with Association Rule Mining Algorithm, IJCSI International Journal of Computer Science Issues ISSN (Online): 1694 0814. Impact Factor - 0.242, Vol. 8, Issue 3, No. 2, May 2011

[7] Martin.A, V. Prasanna Venkatesan, "To find most impact financial features on bankruptcy models using Genetic Algorithm", Proceedings of International conference on Advances in Engineering and Technology [ICAET-2011]. ISBN 978-1-4507-6433-9, E.G.S. Pillay Engineering College, Nagapattin ma, India, 27-28, May, 2011
[8] A. Martin, V. Gayathri, G. Saranya, P. Gayathri, Dr. V. Prasanna Venkatesan, A hybrid model for bankruptcy Prediction using genetic Algorithm, fuzzy c-means and mars, International Journal on Soft Computing ( IJSC ) ISSN: 2229 - 6735 [Online] ; 2229 - 7103 [Print], Vol.2, No.1, February 2011

[9] A. Martin, J. Madhusudhnan, T. Miranda Lakshmi, V. Prasanna Venkatesan, To Find Best Bankruptcy Model using Genetic Algorithm, CiiT International Journal of Artificial Intelligent Systems and Machine Learning Print: ISSN 0974 - 9667 \& Online: ISSN 0974 - 9543, Impact Factor-0.765, Vol. 8, Is sue 1,2011

[10] Martin. A, T. Miranda Lakshmi, V. Prasanna Venkatesan, "A Business Intelligence Framework for Business Performance using Data Mining Techniques", IEEE International Conference on Emerging Trends in Science, Engineering, \& Technology (INCOSET", 2012), J.J. College of Engineering and Technology, Tiruchirappalli, India, 13-14, Dec, 2012

[11] Martin.A,T. Miranda Lakhmi, Dr.V. Prasanna Venkadesan, "An Analysis on Business Intelligence Models to Improve Business Performance", Proceedings of IEEE International Conference on Advances in Engineering, Science and Management - [ICAESM 2012]. ISBN 97881-909042-2-3, E.G.S. Pillay Engineering Co llege, Nagapattinma, India, 30 \& 31, March 2012

[12] Martin,T. Miranda Lakshmi, Dr. V. Prasanna Venkatesan, "A Study on Business Intelligence Models to Identify the BI Model for Business Performance", Proceedings of National Conference on National Conference on Information Technology (NCIT - 2012), Dept. of IT, Pondicherry Engineering College, Puducherry, 15, Feb,2012e

[13] A. Martin, V. Aswathy, S. Balaji and V. Prasanna Venkatesan, An Analysis on Qualitative Bankruptcy Models to Frame Bankruptcy Prediction Rules using Ant Colony Algorithm, CiiT International Journal of Automation and Autonomous Systems ISSN 0974-9659, Impact Factor-0.501, Vol.3, No.8,Oct' 2011

[14] Martin.A, V.Aswathy, S.Balaji, T. Miranda Lakshmi, Dr.V. Prasanna Venkatesan," An Analysis on Qualitative Bankruptcy Prediction Using Fuzzy ID3 and Ant Colony Optimization Algorithm", Proceedings of IEEE International conference on Pattern Recognition, Informatics and Medical Engineering [PRIME 2012]. ISBN:978-1-4673-1037-6, Periyar University, Salem, Tamilnadu, India, 21-23, March 2012

[15] Martin.A, S. Balaji, V. Prasanna Venkatesan, Effective Prediction of Bankruptcy based on the Qualitative factors using FID3 Algorithm, 
International Journal of Computer Applications. ISSN 0975 - 8887, Impact Factor 0.835, Vol. 43, No. 21, Apr'2012

[16] Martin.A, V. Aswathy, V. Prasanna Venkatesan, Framing Qualitative Bankruptcy Prediction Rules Using Ant Colony Algorithm, International Journal of Computer Applications, ISSN 0975 8887, Impact Factor 0.835, Vol. 41, No. 21, Mar' 2012

[17] Martin.A, R. Kethar sri gowri, V.Aishwarya, A. Abinaya, V.Prasanna Venkatesan, "Survey on Applications of Ant Colony Optimization in Bankruptcy Prediction", Proceedings of Third National Conference on Computing Concepts in Current Trends (NC4T'12), Dept. of Computer Applications, Sathyabama University, Chennai, 23-24, Aug, 2012

[18] Myoung-Jong Kim, Ingoo Han, The discovery of experts' decision rules from qualitative bankruptcy data using genetic algorithms, Expert Systems with Applications 25 (2003) 637-646

[19] Hui-Ling Chen, Bo Yang, Gang Wang, Jie Liu, Xin Xu, Su-Jing Wang, Da-You Liu.(2011). A novel bankruptcy prediction model based on an adaptive fuzzy k-nearest neighbour method. Elsevier Journal of Knowledge-Based Systems, 24,1348-1359.

[20] Hui Li, Jie Sun.(2012). Case-based reasoning ensemble for business failure prediction: A computational approach from multiple case representations. Elsevier Journal of Expert Systems with Applications, 39(3), 3298-3310.

[21] Altman EI. (1968). Financial ratios discriminant analysis and the prediction of corporate bankruptcy. Journal of Finance, 23,589-609.

[22] Beaver, W. (1966). Financial Ratios as Predictors of Failure. Empirical Research in Accounting, Supplement to Journal of Accounting Research, 71-111.

[23] Ohlson JA. (1980). Financial ratios and probabilistic prediction of bankruptcy. Journal of Accounting Research, 18,109-31.

[24] West, R C (1985) A factor analytic approach to bank condition. Journal of Banking and Finance, 9, 253-266.

[25] Ravisankar, P., Ravi, V., Bose, I. (2010). Failure prediction of dotcom companies using neural network-genetic programming hybrids. Elsevier Journal of Information Sciences, 180, 1257-1267.

[26] Fengyi Lin, Ching-Chiang Yeh, Meng-Yuan Lee, The use of hybrid manifold learning and support vector machines in the prediction of business failure, Journal Knowledge-Based Systems, Volume 24 Issue 1, February, 2011, Pages 95-101
[27] Arezoo Aghaie, Ali Saeedi, Using Bayesian Networks for Bankruptcy Prediction: Empirical Evidence from Iranian Companies, 2009 International Conference on Information Management and Engineering, pp. 450-455

[28] Martens, David, Fawcett, Tom and Baesens, Bart (2011) Editorial survey: swarm intelligence for data mining. [in special issue: Swarm Intelligence] Machine Learning, 82, (1), 1-42.

[29] K. N. V. D. Sarath Vadlamani Ravi, Association rule mining using binary particle swarm optimization, Journal Engineering Applications of Artificial Intelligence archive Volume 26 Issue 8, September, 2013, Pages 1832-1840

[30] Kasirga Yildirak, Ömür Süer , Kasirga Yildirak, Ömür Süer , The Importance of Qualitative Factors in Firm Default: Evidences from Turkey, CiteSeerX, ULR: http://citeseerx.ist.psu.edu/viewdoc/summary?doi= 10.1.1.225.7208 - [Retrieved on 03/September/2013]

[31] Yi-Chung $\mathrm{Hu}$, Bankruptcy prediction using ELECTRE-based single-layer perceptron, Journal of Neuro computing, Volume 72 Issue 13-15, August, 2009, Pages 3150-3157

[32] Neşe Yalçın Seçme, Ali Bayrakdaroğlu, Cengiz Kahraman, Fuzzy performance evaluation in Turkish Banking Sector using Analytic Hierarchy Process and TOPSIS, Expert Systems with Applications, Volu me 36, Issue 9, November 2009, Pages 11699-11709

[33] Rafael S. Parpinelli, Heitor S. Lopes, Alex A. Freitas, Data Mining With an Ant Colony Optimization Algorithm, IEEE transactions on evolutionary computing, Vol. 6, No. 4, August 2002.

[34] Rafael S. Parpinelli, Heitor S. Lopes, Alex A. Freitas, An Ant Colony Algorithm for Classification Rule Discovery, Chapter X, Idea Group Publishing, pp.190-208, 2002

[35] Khodadadi Vali, Abolfazl (Parviz) Zandimia, Nouri Marzieh, Application of Ants Colony System for bankruptcy Prediction of Companies Listed in Theran Stock Exchange, Business Intelligence Journal 01/2010

[36] Neşe Yalçın Seçme, Ali Bayrakdaroğlu, Cengiz Kahraman,Fuzzy performance evaluation in Turkish Banking Sector using Analytic Hierarchy Process and TOPSIS, Expert Systems with Applications, Volume 36, Issue 9, November 2009, Pages 11699-11709

[37] Shuihua Wang, Lenan Wu1, Yudong Zhang, Zhengyu Zhou, Ant colony algorithm used for bankruptcy prediction, Information Science and Engineering (ISISE), 2009 Second International 
Symposium on, Date of Conference: 26-28 Dec. 2009, Page(s):137 - 139 E-ISBN :978-1-42446326-8

[38] Bo Liu, Hussein A. Abbass, Bob McKay, Classification Rule Discovery with Ant Colony Optimization, IEEE Computational Intelligence Bulletin, Vol 3, No 1, 2004.

[39] Karthikeyan.T, Mohana Sundaram.J, A Study on Ant Colony Optimization with Association Rule, International Journal of Advanced Research in Computer Science and Software EngineeringISSN: 2277 128X, Volume 2, Is sue 5, May 2012

[40] Allen Chan and Alex Freitas, A New Classification-Rule Pruning Procedure for an Ant Colony Algorithm, Proceeding EA'05 Proceedings of the 7th international conference on Artificial Evolution, Springer-Verlag Berlin, Heidelberg, 2005, Pages 25-36

[41] Rafael S. Parpinelli, Heitor S. Lopes, Alex A. Freitas, Data Mining with an Ant Colony Optimization Algorithm, 2002, http://sci2s.ugr.es/keel/pdf/algorithm/articulo/AntIEEE-TEC.pdf [Retrieved on April, 2013]

[42] P. Ravi Kumar, V. Ravi, Bankruptcy prediction in banks and firms via statistical and intelligent techniques - A review, European Journal of Operational Research, Volume 180, Issue 1, 1 July 2007, Pages 1-28

[43] Ervin L. Black, F. Greg Burton and Peter M. Johnson," Qualitative Factors as Determinants of Continued Success: An Examination of eBusiness Entrepreneurial Firms Using the New Venture Template ${ }^{\mathrm{TM}}$ ", The Journal of Entrepreneurial Finance Volume 13, Issue 2, ISSN: 1551-9570, 2009.

[44] Tony White, Ant Colony Optimization and the Ant-Miner Algorithm (2006), http://citeseerx.ist.psu.edu/viewdoc/summary?doi= 10.1.1.83.6718 [Retrieved on 05/Sep'/2013]

\section{Authors' Profiles}

Mr. A. Martin, Assistant Professor in the Department of Information Technology in Sri Manakula Vinayagar Engineering College, Pudhucherry, India. He holds a M.E and pursuing his Ph.D in Banking Technology from Pondicherry University, India. His areas of interest are bankruptcy prediction techniques, business intelligence and information delivery models

Mrs. T. Miranda Lakshmi, Assistant Professor in the Department of Computer science, St.Joseph's College (Autonomous) Cuddalore, India. She is pursuing Ph.D in Computer Science from Bharathiar University, Coimbatore, India. Her area of interest is Business
Intelligence and multi criteria decision making techniques.

Dr.V.Prasanna Venkatesan, Associate Professor, Dept. of Banking Technology, Pondicherry University, Pondicherry. He has more than 20 years teaching and research experience in the field of Computer Science and Engineering and Banking Technology. He has developed an Architectural Reference Model for Multilingual Software. His area of interest is SOA, software engineering, software patterns evaluation, business intelligence and smart computing.

How to cite this paper: A. Martin, T. Miranda Lakshmi, V. Prasanna Venkatesan,"An Analysis on Qualitative Bankruptcy Prediction Rules using Ant-Miner", International Journal of Intelligent Systems and Applications(IJISA), vol.6, no.1, pp.36-44, 2014. DOI: 10.5815/ijisa.2014.01.05 